\title{
Signal duration and choosing between signaled and unsignaled reward
}

\author{
KATHLEEN A. RYAN and PIETRO BADIA \\ Bowling Green State University, Bowling Green, Ohio 43403
}

\begin{abstract}
The effects of signal duration when choosing between signaled and unsignaled responseindependent reinforcers were examined in two experiments. In Experiment 1, albino rats were given a choice between signaled and unsignaled food delivered on variable-time 60-sec schedules using a 20-sec signal. All subjects preferred the signaled schedule at a level comparable to that reported in an earlier study using a 5-sec signal. Experiment 2 presented six rats with a direct choice between a 5-sec and a 20-sec signal condition, and three rats with a choice between a 1.5-sec and a 5-sec signal duration. Subjects preferred the 20-sec signal over the 5-sec signal, but no preference was found with the 1.5-sec vs. a 5-sec signal. Current theoretical views, such as delay reduction and behavioral competition, are considered.
\end{abstract}

Badia, Ryan, and Harsh (1981) recently reported that subjects, given a choice, preferred signaled over unsignaled food schedules with food pellets or chocolate milk as reinforcers and with response-dependent or -independent procedures. The present study provides further information about the conditions under which subjects prefer signaled over unsignaled schedules. In addition, it provides information related to the delay-reduction hypothesis of Fantino (1977) as well as the behavioral competition view of Green and Rachlin (1977).

Efforts to explain preference for signaled food schedules focus on the reinforcing properties of the signal. Fantino (1977) suggests that the reinforcing value of the signal is a function of the reduction in time to the reinforcer correlated with its onset. This delay-reduction view suggests that preference for the signaled food schedule is a function of the extent to which the signal reduces the time to reinforcement. For example, a 5-sec signal on a variable time (VT) 60 -sec schedule produces a $92 \%$ reduction in time to reinforcement (of an original average waiting time of $60 \mathrm{sec}$, only $5 \mathrm{sec}$, or $8 \%$, remain when the signal appears). Therefore, given a choice between a signaled schedule and an unsignaled one, subjects should choose the signaled schedule. Recent findings indicate that subjects do, in fact, strongly prefer the signaled schedule (Badia et al., 1981) when the signal is $5 \mathrm{sec}$. Would they prefer the signaled schedule if the signal were extended to $20 \mathrm{sec}$ ? Since a $20-\mathrm{sec}$ signal duration results in smaller reduction in the delay to reinforcement than the 5-sec signal, preference for the signaled schedule, if it occurs, should be weaker. Experiment 1

This research was supported in part by Grant GB-33725 from the National Science Foundation and funds from the Faculty Research Committee of Bowling Green State University. Reprints may be obtained from Pietro Badia, Department of Psychology, Bowling Green State University, Bowling Green, Ohio 43403. gave subjects a choice between signaled and unsignaled food schedules in which the signal was 20 sec. The procedure was identical to that used by Badia et al. (1981), in which the signal was 5 sec.

\section{EXPERIMENT 1}

\section{Method}

Subjects. Ten experimentally naive female albino rats (90-120 days old) of the Sprague-Dawley strain (Holtzman Co.) were maintained at $80 \%$ of their free-feeding weights. The subjects were individually housed with free access to water.

Apparatus. The subjects were tested in standard Foringer operant conditioning chambers $(25 \times 23 \times 25 \mathrm{~cm})$ housed in sound. attenuating boxes. Two levers were mounted on the $25-\mathrm{cm}$ wall, $7 \mathrm{~cm}$ above the floor and $4 \mathrm{~cm}$ from either side. Each chamber was fitted with a Plexiglas ceiling $12 \mathrm{~cm}$ above the grid floor. The beginning of the experimental session was identified by the termination of light provided by a $24-\mathrm{V}$ dc bulb, capped by a $1.25-\mathrm{cm}$ jeweled lens, and mounted $6 \mathrm{~cm}$ above the right lever. The onset of this light identified the end of the session. A tone generator (Mallory Sonalert) mounted $10 \mathrm{~cm}$ above the right lever produced a $4,500-\mathrm{Hz}$ tone at $80 \mathrm{~dB}$ and served as the prefood signal. The correlated stimulus identifying the signaled schedule was either the onset or termination of light provided by two $24-\mathrm{V}$ dc bulbs, each with a $2.5-\mathrm{cm}$ white jeweled lens cap. These lights were mounted $16 \mathrm{~cm}$ above each lever. For other subjects, the discriminative stimulus identifying the signaled or unsignaled schedule was the reverse.

Commercially available low-fat ( $1 / 2 \%$ milkfat) chocolate milk was used as a reinforcer. A solenoid mounted on the outside of the sound-attenuating box delivered $.10-\mathrm{cc}$ injections of chocolate milk into a brass cup through a standard-size drinking tube located between the two levers. The drinking tube was shielded so that the animal could not lick the tip and drain the tube of the liquid.

Procedure. Subjects were tested in 3-h daily sessions. Reinforcers were delivered independently of responding on a VT 60 -sec schedule generated by the Fleshler and Hoffman (1962) tables. The minimum interfood interval was $21 \mathrm{sec}$ for a 20 -sec signal. Both levers were equally effective as changeover levers.

Six subjects were given a choice between a signaled schedule and an unsignaled one. During the signaled schedule, a 20-sec tone always preceded the delivery of food. During the unsignaled schedule, a tone did not occur. The remaining four subjects were given 
a choice between two unsignaled schedules. In one unsignaled schedule a 20-sec tone occurred explicitly unpaired with delivery of food. The explicitly unpaired tone occurred on a VT 60-sec schedule generated by the Fleshler and Hoffman (1962) tables. In the other unsignaled schedule, the tone did not occur. The procedure was the same for all subjects and consisted of a training-baseline phase followed by a choice phase.

The subjects received a minimum of six training-baseline sessions consisting of an equal number of exposures to both schedules. For Subjects EU1, EU2, and EU4, light identified the signaled schedule and darkness identified the unsignaled schedule. For Subjects EU3, EU5, and EU6, this was reversed. For Subjects UL1 and UL6, light identified the explicitly unpaired-tone/unsignaled schedule and darkness, the no-tone/unsignaled schedule. The discriminative stimuli were reversed for Subjects UL2 and UL4.

During the baseline period, responses on the changeover levers did not produce a stimulus change, but responses and the time that would have been spent in the changeover condition, had the responses been effective, were recorded and served as baseline data. The stability requirement for baseline conditions and all other test conditions described below was three consecutive sessions in which the percentage of time in the changeover condition varied no more than $10 \%$ between sessions. Exceptions to the criterion were allowed if performance variability persisted over many sessions. These exceptions occurred infrequently.

Following the training-baseline sessions, subjects were given the opportunity to change from the unsignaled to the signaled schedule, and vice versa (choice phase). The order in which subjects received a changeover condition differed, with half the subjects given the opportunity to change to the unsignaled schedule first and half given the reverse order. A response on the changeover lever terminated the existing schedule and produced the alternate schedule for $1 \mathrm{~min}$. Further responding on the changeover levers during this period had no effect. At the end of the 1-min changeover period, the alternate schedule and the stimulus associated with that schedule terminated and the initial schedule was reinstated. Subjects could remain under this initial schedule or they could reinstate the alternate one. Changeover responding had no effect on the delivery of reinforcers, but served only to produce either the signaled or the unsignaled schedule, both of which were controlled by the same interval programmer. The measure of preference was the percentage of session time spent in the alternate schedule. Two replications of each changeover condition were given.

\section{Results}

Data for the six subjects choosing between signaled and unsignaled schedules are presented in Figure 1, which shows the percentage of time spent in the changeover condition for the last 3 days of the trainingbaseline and choice phases. Columns labeled "Baseline" represent the percentage of time spent in mock changeover when the changeover contingency was not in effect. All subjects, with the exception of EU2, main-

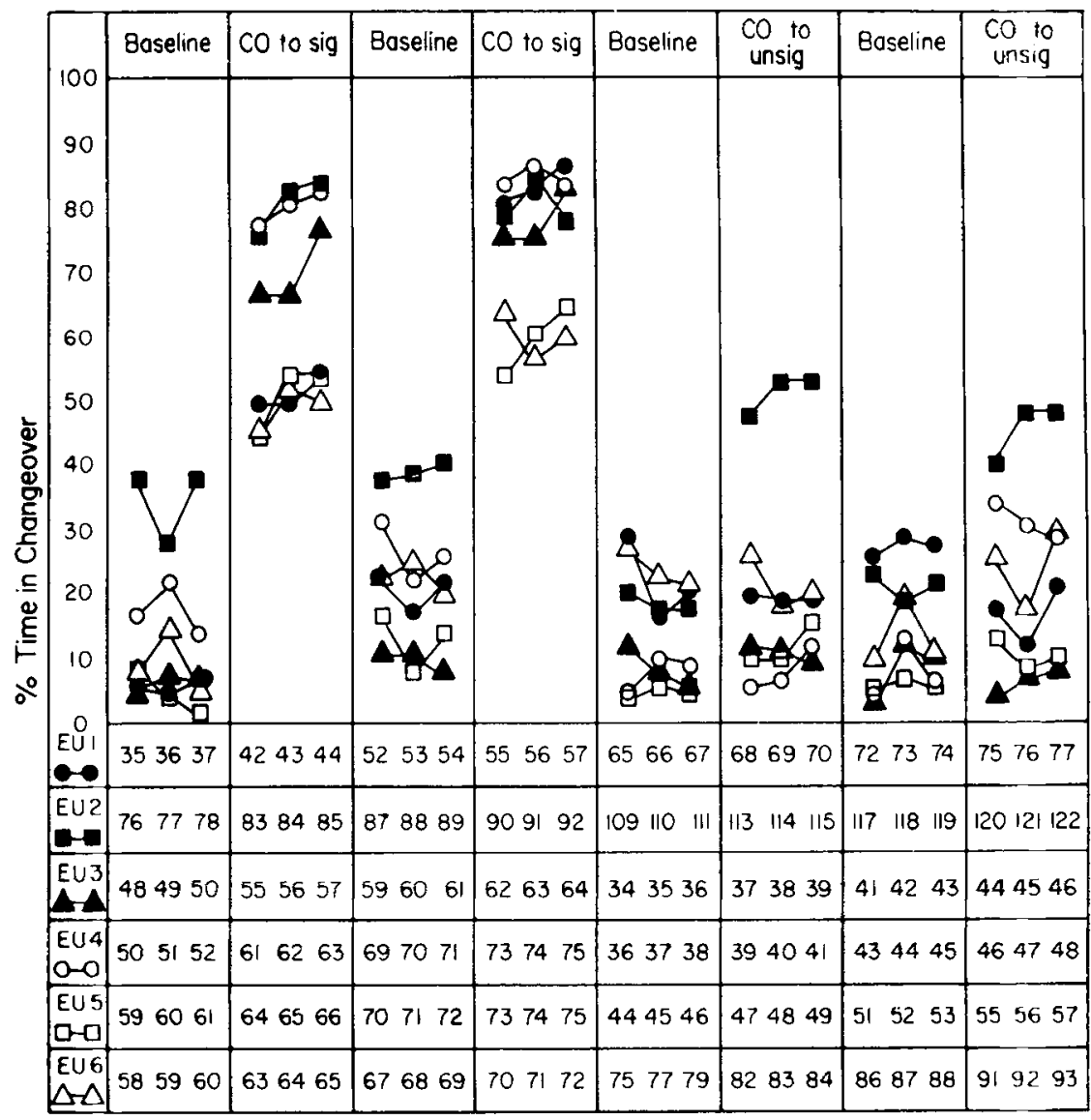

Three hour sessions

Figure 1. Percentage of seasion time spent in the last 3 days of each condition given a choice between signaled and unalgnaled schedules. Sesolon numbers indicate the order in which cholce was given. 
tained a baseline lever performance between $10 \%$ and $20 \%$ of the mock-changeover condition. Subject EU2 had a slightly higher baseline performance. The columns labeled "CO to sig" represent the percentage of time spent in the changeover condition when the changeover response produced the signaled condition. The columns labeled " $\mathrm{CO}$ to unsig" represent the percentage of time spent in the changeover condition when the changeover response produced the unsignaled schedule. All six subjects responded sufficiently to spend the majority of the session in the signaled schedule. In contrast, with the exception of Subject EU2, none of the subjects responded to produce the unsignaled schedule when given the opportunity. Subject EU2 responded only slightly over baseline for the unsignaled schedule but considerably over baseline for the signaled schedule. The rate and pattern of responding for the signaled schedule were consistent for all subjects. Most responses were functional and under discriminative control, occurring only when they produced changeover periods, that is, after the initial response, few nonfunctional responses occurred during the 1 -min changeover period.

Table 1 represents the mean percentage of time spent in changeover for the last 3 days of baseline and choice conditions for subjects given a choice between two unsignaled schedules, only one of which contained a 20-sec explicitly unpaired tone. Rows labeled "Sessions" refer to the number of sessions spent in each condition. For example, during the first exposure to the baseline condition, Subject UL1 took 20 sessions to achieve stability and, during the last three sessions, responded to spend an average of $9 \%$ of the session in changeover. Generally, the results did not show a consistent tendency among subjects to respond for either schedule. Subjects UL1, UL4, and UL6 responded slightly over baseline for the ex-

Table 1

Mean Percentage of Time Spent in Changeover

\begin{tabular}{|c|c|c|c|c|c|c|c|c|}
\hline \multirow[b]{3}{*}{ Condition } & \multicolumn{8}{|c|}{ Subject } \\
\hline & \multicolumn{2}{|c|}{$\begin{array}{c}\text { UL1 } \\
\text { Exposure }\end{array}$} & \multicolumn{2}{|c|}{$\begin{array}{c}\text { UL2 } \\
\text { Exposure }\end{array}$} & \multicolumn{2}{|c|}{$\begin{array}{c}\text { ULA } \\
\text { Exposure }\end{array}$} & \multicolumn{2}{|c|}{$\begin{array}{c}\text { UL6 } \\
\text { Exposure }\end{array}$} \\
\hline & 1 & 2 & 1 & 2 & 1 & 2 & 1 & 2 \\
\hline $\begin{array}{l}\text { Baseline } \\
\text { Sessions }\end{array}$ & $\begin{array}{r}9.0 \\
20\end{array}$ & $\begin{array}{r}6.3 \\
4\end{array}$ & $\begin{array}{r}6.7 \\
4\end{array}$ & $\begin{array}{r}4.7 \\
4\end{array}$ & $\begin{array}{r}2.0 \\
4\end{array}$ & $\begin{array}{r}8.7 \\
4\end{array}$ & $\begin{array}{r}1.7 \\
8\end{array}$ & $\begin{array}{r}10.0 \\
4\end{array}$ \\
\hline $\begin{array}{l}\mathrm{CO} \text { to Tone } \\
\text { Sessions }\end{array}$ & $\begin{array}{r}25.0 \\
9\end{array}$ & $\begin{array}{r}18.7 \\
4\end{array}$ & $\begin{array}{r}3.0 \\
5\end{array}$ & $\begin{array}{r}4.7 \\
3\end{array}$ & $\begin{array}{r}23.3 \\
3\end{array}$ & $\begin{array}{r}19.0 \\
4\end{array}$ & $\begin{array}{r}26.7 \\
5\end{array}$ & $\begin{array}{r}30.7 \\
4\end{array}$ \\
\hline $\begin{array}{l}\text { Baseline } \\
\text { Sessions }\end{array}$ & $\begin{array}{r}7.7 \\
4\end{array}$ & $\begin{array}{r}3.3 \\
4\end{array}$ & $\begin{array}{r}2.3 \\
4\end{array}$ & $\begin{array}{r}8.3 \\
4\end{array}$ & $\begin{array}{r}5.3 \\
6\end{array}$ & $\begin{array}{r}1.0 \\
4\end{array}$ & $\begin{array}{r}16.3 \\
4\end{array}$ & $\begin{array}{r}14.0 \\
4\end{array}$ \\
\hline $\begin{array}{l}\text { CO to No-Tone } \\
\text { Sessions }\end{array}$ & $\begin{array}{r}4.0 \\
3\end{array}$ & $\begin{array}{r}5.3 \\
3\end{array}$ & $\begin{array}{r}19.3 \\
5\end{array}$ & $\begin{array}{r}31.7 \\
3\end{array}$ & $\begin{array}{r}.6 \\
3\end{array}$ & $\begin{array}{r}2.3 \\
3\end{array}$ & $\begin{array}{r}14.0 \\
3\end{array}$ & $\begin{array}{r}11.7 \\
3\end{array}$ \\
\hline
\end{tabular}

Note-Time spent in changeover for the last 3 days of baseline and choice conditions for subjects given a choice between two unsignaled schedules, one of which contained an explicitly unpaired tone. Sessions refer to the number of sessions spent in each condition. plicitly unpaired tone schedule, while Subject UL2 responded slightly over baseline for the no-tone schedule. None of the subjects, however, indicated a clear preference for one schedule over the other, indicating that the tone had neither attractive nor aversive properties when uncorrelated with reinforcement.

\section{EXPERIMENT 2}

Comparisons of the percentage of time spent in the signaled schedule between Experiment 1 of the present study (20-sec signal) and the Badia et al. (1981) study, which used a 5-sec signal, indicate relatively little difference in the magnitude of preference. Subjects in the Badia et al. study spent approximately $65 \%-80 \%$ of the experimental sessions in the signaled schedule. The results of Experiment 1 show that four subjects spent $70 \%-80 \%$ and two spent $55 \%-60 \%$ of the session in the signaled schedule. Comparison of the earlier study (Badia et al., 1981) with results of the present one permits the conclusion that subjects prefer a predictable food schedule with either a 5 - or a $20-\mathrm{sec}$ signal. Since the results of the two studies are so similar, they also suggest that there is little difference in the reinforcing value of 5 - and 20 -sec signals. In this regard, the results do not support the delay-reduction hypothesis, since this hypothesis predicts that shorter signal durations are more reinforcing. Such a conclusion, however, may be both unfair and premature, since definitive statements regarding which signal duration is more reinforcing cannot be made on the basis of two nonparametric studies done at different times. It may also be that the difference in reduction in delay to reinforcement between the 5- and $20-\mathrm{sec}$ signals, with a reinforcement interval of $60 \mathrm{sec}$, was not sufficient to affect preference. There may also be unstated boundary conditions under which the delayreduction hypothesis operates. For example, it may be that the delay-reduction hypothesis is effective only when subjects can contrast different delay-toreinforcement time periods. The latter would require a "within-subjects" approach, in which the same subject experiences at least two different signal durations. The second experiment does this.

Experiment 2 provides a direct comparison between two different signal durations by pitting them against each other. Some subjects were allowed to choose between 5- and 20-sec signals, and others, between 1.5and S-sec signals.

\footnotetext{
Method

Nine experimentally naive rats, similar to those of Experiment 1, were used. They were housed and maintained as in Experiment 1.

The apparatus and procedure were the same as in Experiment 1, except that the choice alternatives involved two signaled schedules. For six subjects, the choice was between a 5-sec tone and a 20 -sec tone preceding food, and for three subjects, the choice was between a 1.5-sec tone and a 5-sec tone preceding food. For Subjects GL3, GLA, GL7, and GL9, light identified the condition with the longer
} 
signal and darkness identified the condition with the shorter signal. For Subjects GL6, GL8, GL10, and GL11, it was the reverse. Subjects GL5, GL10, and GL11 were first given an option to change from the 20-sec to the 5-sec signaled schedule, and then later the reverse option was given. This order was reversed for Subjects GLS, GL7, and GL9.

\section{Results}

The percentage of time spent in the changeover condition for the last 3 days of baseline and choice is presented in Figure 2. The columns labeled " $\mathrm{CO}$ to 5 -sec signal" represent the choice condition in which a response changed from a $20-\mathrm{sec}$ to a $5-\mathrm{sec}$ signaled schedule. The columns labeled "CO to 20-sec signal" represent the choice condition in which a response changed from a 5-sec to a $20-\mathrm{sec}$ signaled schedule. As seen in Figure 2, when given the option, subjects did not respond above baseline levels to produce the 5-sec signaled schedule. However, when given the option to produce the 20-sec signaled schedule, they responded at a rate sufficient to spend $70 \%-80 \%$ of the session in that schedule. Performance was remarkably similar for all subjects for both the initial exposure to the conditions and again later when the conditions were replicated.

Table 2 represents the mean percentage of time spent in changeover for the last 3 days of baseline and choice conditions for subjects given a choice between a $1.5-\mathrm{sec}$ and a $5-\mathrm{sec}$ signaled condition. Results indicate that subjects did not respond significantly over baseline for either schedule. Observation of the subjects revealed no systematic behavior patterns that
Table 2

Mean Percent of Time Spent in Changeover

\begin{tabular}{|c|c|c|c|c|c|c|}
\hline \multirow[b]{3}{*}{ Condition } & \multicolumn{6}{|c|}{ Subject } \\
\hline & \multicolumn{2}{|c|}{$\begin{array}{c}\text { GL3 } \\
\text { Exposure }\end{array}$} & \multicolumn{2}{|c|}{$\begin{array}{c}\text { GL4 } \\
\text { Exposure } \\
\end{array}$} & \multicolumn{2}{|c|}{$\begin{array}{c}\text { GL8 } \\
\text { Exposure } \\
\end{array}$} \\
\hline & 1 & 2 & 1 & 2 & 1 & 2 \\
\hline Baseline & 4.0 & 1.3 & 1.0 & 21.3 & .7 & 1.0 \\
\hline Sessions & 4 & 4 & 6 & 6 & 4 & 4 \\
\hline $\mathrm{CO}$ to $1.5 \mathrm{sec}$ & 2.3 & 1.3 & 21.7 & 22.7 & 3.0 & 1.3 \\
\hline Sessions & 3 & 3 & 5 & 5 & 3 & 3 \\
\hline Baseline & 1.3 & 1.3 & 34.7 & 13.0 & 1.7 & 1.3 \\
\hline Sessions & 4 & 4 & 4 & 4 & 4 & 4 \\
\hline $\mathrm{CO}$ to $5.0 \mathrm{sec}$ & 1.3 & 3.3 & 14.3 & 10.7 & 1.3 & 2.3 \\
\hline Sessions & 3 & 3 & 10 & 7 & 3 & 3 \\
\hline
\end{tabular}

Note-Time spent in changeover for the last 3 days of baseline and choice conditions for subjects given a choice between two unsignaled schedules, one of which contained an explicitly unpaired tone. Sessions refer to the number of sessions spent in each condition.

might have explained lack of responding (e.g., sleeping). The lack of preference for these subjects contrasted sharply with subjects given a choice between the 5- and 20-sec signaled schedules.

\section{DISCUSSION}

The delay-reduction hypothesis states that the strength of a stimulus as a conditioned reinforcer is a function of the reduction in time to reinforcement

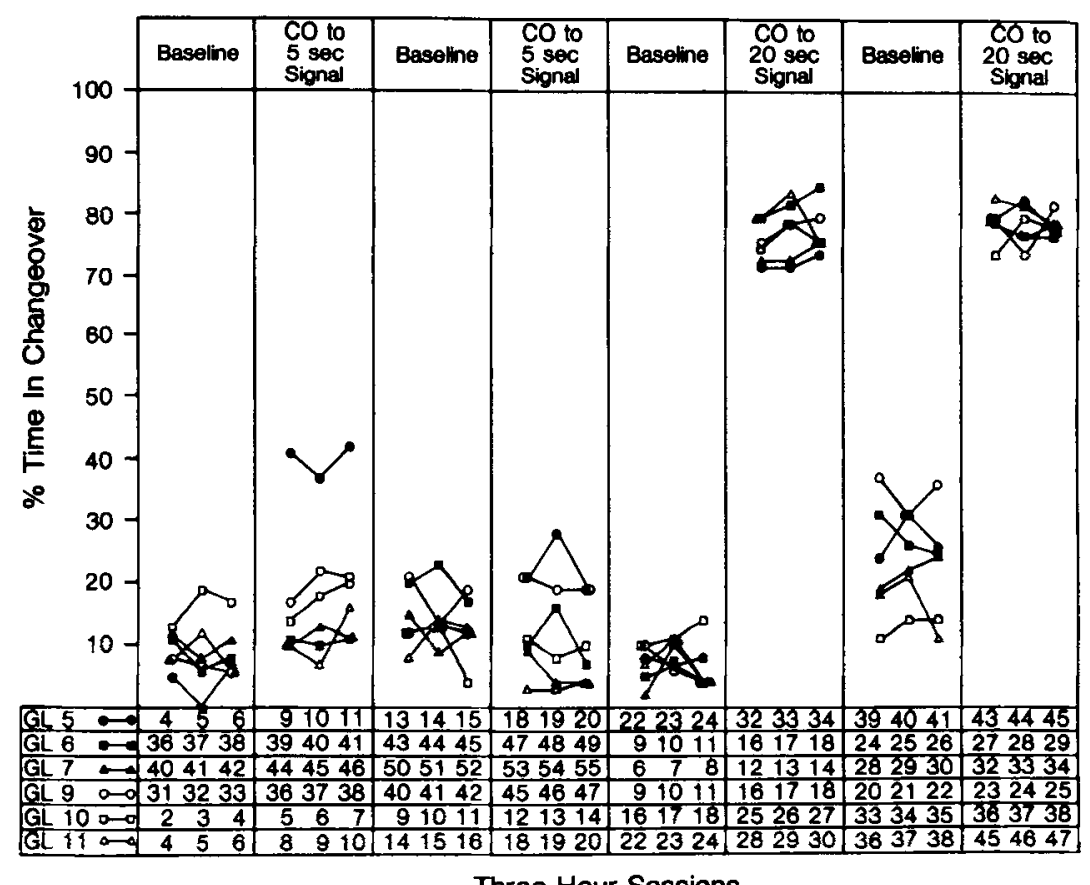

Three Hour Sessions

Figure 2. Percentage of session time spent in the last 3 days of each condition for subjects given a choice between a 5 -sec and a 20 -sec signaled schedule. Session numbers Indicate the order In which choice was given. 
correlated with the onset of that stimulus (Fantino, 1977). If food was delivered on a VT 60-sec schedule, a 5-sec signal would be a stronger conditioned reinforcer than a 20 -sec signal, since a 5 -sec signal is correlated with a $92 \%$ reduction in time to primary reinforcement (of the original average waiting time of $60 \mathrm{sec}$, only $5 \mathrm{sec}$, or $8 \%$, remain once the signal appears), while a 20 -sec signal is correlated with only a $67 \%$ reduction in time to primary reinforcement (of an original average waiting time of $60 \mathrm{sec}, 20 \mathrm{sec}$, or $33 \%$, still remain once the signal appears). Thus, subjects should prefer the signaled schedule correlated with the greatest reduction in time to reinforcement.

That subjects prefer a signaled over an unsignaled schedule (Experiment 1) is consistent with the delayreduction hypothesis. The results of Experiment 2, however, do not offer a direct test of the delay reduction view, since the procedure involved choosing between schedules differing in both delay reduction and in the probability of receiving the signal. Even though the frequency of occurrence is the same for each signal duration, it is far more likely that a signal will be immediately encountered when changing from the 5to the 20-sec signaled schedule $(p=.33)$ than when changing in the reverse direction $(p=.08$; these $p$ values are based on the mean interfood interval of $60 \mathrm{sec}$ ). It could be argued that preference for one signal duration over another is a function of both delay reduction and the probability of the signal, that is, conditioned reinforcement following a changeover response. Under conditions of equiprobable schedule components (e.g., McMillan, 1974), a delay-reduction view may predict preference for the schedule correlated with the shortest delay to reinforcement. However, if these two opposing factors are operating, the results of Experiment 2 suggest that probability of reinforcement is more influential on choice than is delay reduction.

It is not obvious why subjects did not prefer the 5over the 1.5-sec signaled schedule. We can speculate on some of the possible reasons. Since a 5-sec signaled schedule is preferred over an unsignaled schedule (Badia et al. 1981), it is clear that a signal duration of this length is discriminable and reinforcing. That the 5-sec signaled schedule was not preferred over the 1.5-sec schedule may suggest that both signal durations were equally attractive. It is also possible that the discrimination between the 1.5- and 5-sec signaled schedules was too difficult and that, because of this, subjects failed to show a preference. Some would argue that this parsimonious view be rejected since it has been shown that rats can easily discriminate the presence of stimuli with durations of $.5 \mathrm{sec}$ (e.g., Migler, 1963). However, while rats can discriminate the presence of stimuli at short intervals and respond in their presence, they may be unable to discriminate the temporal difference in stimulus durations between two such stimuli. The latter may be especially difficult when the discrimination procedure is a successive one with long time periods between presentations of the two stimuli (as in Experiment 2). This discrimination notion could be assessed by beginning with an "easy" discrimination task, for example, choosing between 5 - and 20-sec signaled schedules and then progressing to a shorter, more difficult one, for example, choosing between 1.5- and 5-sec signaled schedules (cf. Lawrence, 1952).

Interestingly, behavioral observations of subjects in the 5- and 20-sec signaled schedules revealed few differences. Whenever the signal appeared under either schedule, the same pattern of behavior emerged: Subjects exhibited an orienting response, immediately followed by a termination of current behavior (e.g., grooming, exploratory behavior) and movement toward the food cup. Once at the food cup, the subject would place its nose into the cup and lick the cup and the surrounding area until delivery of the chocolate milk. After ingesting the chocolate milk, the subject moved away from the cup. These food-related behaviors occurred in the presence of the signal for all signaled schedules, but was most prominent for the 5- and 20-sec schedules. That is, during the 5- and 20-sec signaled schedules, subjects performed foodrelated behaviors throughout the entire signal interval. During the signal-absent periods, food-related behavior seldom occurred.

The different behavior patterns that emerged during signal-present and signal-absent periods lead to speculation about a hypothesis first proposed by Green and Rachlin (1977) to account for pigeons' preference for informative stimuli and later applied to behavioral contrast (Hinson \& Staddon, 1978). The hypothesis relates to interim and terminal behaviors described in detail by Staddon and Simmilhag (1971). The hypothesis suggests that the reinforcing value of a predictable schedule lies in the fact that the presence of discriminative stimuli (signal-present and signal-absent periods) increases the time available for the subject to engage in different activities. Food-related behaviors, labeled terminal behaviors, have the highest reinforcing value and occur almost exclusively during the signal, while other behaviors (e.g., grooming, exploratory behavior), labeled interim behaviors, have intrinsic value and occur exclusively during the signalabsent period. Green and Rachlin (1977) have constructed the following hierarchy of behaviors according to reinforcing value: (1) terminal responses preceding food, (2) interim responses preceding food, (3) interim responses preceding (during) signal-absent periods, and (4) terminal responses preceding (during) signalabsent periods. Presumably a signaled schedule allows the subject to obtain the higher valued items, 1 and 3 , and avoid items 2 and 4 . Choosing an unsignaled schedule would require the subject to experience the lower valued items, 2 and 4, at least some of the time.

The results of Experiment 2, together with behav- 
ioral observations, appear to support the view that the longer the opportunity to engage in terminal behaviors, the more reinforcing a particular stimulus situation is. Thus, the longer the signal duration, the greater the reinforcement value. An increase in signal duration, however, is also accompanied by a decrease in the duration of the signal-absent period, which allows for less time for interim responses to occur. Thus, a reduction in the time available for the subject to engage in intrinsically valued interim behaviors may, at some point in time, become aversive and perhaps punishing. Evidence gathered from observing response studies, however, appears to suggest the opposite. A large body of evidence indicates that observing behavior is maintained only by stimuli signaling the positive outcome, suggesting that stimuli which identify the nonoccurrence of food (signal-absent period) may be aversive (e.g., Dinsmoor, Browne, \& Lawrence, 1972; Jenkins \& Boakes, 1973; Mulvaney, Dinsmoor, Jwaideh, \& Hughes, 1974). The application of a behavioral competition hypothesis to the results of the present study is only speculative. Systematic manipulation of the opportunity to engage in interim and terminal behaviors, together with the ability to accurately record the frequency of each type of behavior, is needed. Some of the older views of signal preference, such as the preparation (Perkins, 1968) and information (Wilton \& Clements, 1971) hypotheses are also inadequate in accounting for the present results. The strengths and weaknesses of these approaches have been discussed extensively elsewhere (Kelleher \& Gollub, 1962; Fantino, 1977) and will not be repeated here.

The choice situation may be far more complex than suggested by current theoretical views. Furthermore, not always do subjects choose predictable appetitive events. There are reported instances of subjects preferring unsignaled over signaled food (e.g., Hershiser \& Trapold, 1971). An examination of those studies reporting a preference for unsignaled over signaled food (e.g., Hershiser \& Trapold, 1971; Marcucella \& Margolius, 1978; Badia, Harsh, \& Ryan, Note 1) reveals an interesting similarity. The procedure used in these studies can be described as a noncommitment one. With a noncommitment procedure, subjects can freely switch between predictable and unpredictable schedules and are not required to spend a specified amount of time in a schedule once a choice response is made (e.g., shuttlebox, concurrent schedules). In contrast, a commitment procedure requires subjects to spend a certain amount of time in the schedule chosen. The present study used a commitment choice procedure and required that subjects spend $1 \mathrm{~min}$ in the alternate schedule. Thus, in a noncommitment procedure, the subject can control the duration of exposure to the signal and, more important, the duration of exposure to the signal-absent period of the signaled schedule. The fact that those studies showing preference for unsignaled over signaled food used a noncommitment procedure while other studies generally have used a commitment procedure may have important implications for future theoretical developments regarding predictability and choice.

\section{REFERENCE NOTE}

1. Badia, P., Harsh, J., \& Ryan, K. Choosing signaled over unsignaled reward and vice versa. Paper presented at the meeting of the American Psychological Association, San Francisco, 1977.

\section{REFERENCES}

Badia, P., Ryan, K., \& Harsh, J. Choosing schedules of signaled appetitive events over schedules of unsignaled ones. Journal of the Experimental Analysis of Behavior, 1981, 35, 187-195.

Dinsmoon, J. A., Browne, M. P., \& Lawrence, C. E. A test of the negative discriminative stimulus as a reinforcer of observing. Journal of the Experimental Analysis of Behavior, 1972, 18, 79-85.

Fantino, E. Conditioned reinforcement: Choice and information. In W. K. Honig (Ed.), Handbook of operant behavior. Englewood Cliffs, N.J: Prentice-Hall, 1977.

Fleshler, M., \& Hoffman, H. S. A progression for generating variable-interval schedules. Journal of the Experimental Analysis of Behavior, 1962, 5, 529-530.

Green, L., \& Rachlin, H. Pigeons' preference for stimulus information: Effects of amount of information. Journal of the Experimental A nalysis of Behavior, 1977, 27, 255-263.

Henshiser, D., \& Trapold, M. A. Preferences for unsignaled direct reinforcement in the rat. Journal of Comparative and Physiological Psychology, 1971, 77, 323-328.

Hinson, J. M., \& Staddon, J. E. P. Behavioral competition: A mechanism for schedule interactions. Science, 1978, 202, 432-434.

JENKINS, H. M., \& BoAKEs, R. A. Observing stimulus sources that signal food or no food. Journal of the Experimental Analysis of Behavior, 1973, 20, 197-207.

Kelleher, R. T., \& Gollub, L. R. A review of positive conditioned reinforcement. Journal of the Experimental Analysis of Behavior, 1962, 5, 543-597.

LAWRENCE, D. H. The transfer of a discrimination along a continuum. Journal of Comparative and Physiological Psychology, $1952,45,511-516$.

Marcucella, H., \& Margolius, G. Time allocation in concurrent schedules: The effect of signaled reinforcement. Journal of the Experimental Analysis of Behavior, 1978, 29, 419-430.

MCMillan, J. C. Average uncertainty as a determinant of observing behavior. Journal of the Experimental Analysis of Behavior, 1972, 22, 401-408.

Miglen, B. Bar holding during escape conditioning. Journal of the Experimental Analysis of Behavior, 1963, 6, 65-72.

Mulvaney, D. E., Dinsmoor, J. A., Jwaideh, A. R., \& Hughes, L. H. Punishment of observing by the negative discriminative stimulus. Journal of the Experimental Analysis of Behavior, 1974, 21, 37-44.

Perkins, C. C., Jr. An analysis of the concept of reinforcement. Psychological Review, 1968, 75, 155-172.

Staddon, J. E. R., \& Simmelhag, V. L. The superstition experiment: A re-examination of its implications for the study of adaptive behavior. Psychological Review, 1971, 78, 3-43.

Wilton, R. N., \& Clements, R. O. The role of information in the emission of observing responses: A test of two hypotheses. Journal of the Experimental Analysis of Behavior, 1971, 16, 161-166.

(Manuscript received November 18, 1980; revision accepted for publication September 8, 1981.) 